\title{
TÁTICAS, CIRCUITOS E INVENÇÕES: DISPOSITIVOS DA IRONIA NA ARTE CONTEMPORÂNEA BRASILEIRA
}

Felipe Scovino $^{1}$

\section{Resumo}

O estudo coloca a produção da ironia dentro de um campo amplo (discussões que envolvem a política do mercado de arte, Ética, participação do espectador, o jogo entre aparência e ilusão proporcionado pelo objeto e a relação da ironia com o sexo e o humor negro). Este ensaio estabelece conceitos críticos e constrói o panorama de uma rede de atravessamento do "objeto de arte irônico" em seus diferentes suportes e ações.

Palavras-chave: Arte contemporânea, ironia e crítica.

\begin{abstract}
This paper refers the production of irony within an expanded field (debates that involve Ethics, the politics of the art market, participation of the audience, the play between appearance and illusion within the work of art and the relationship between irony, sex and black humor). This paper establishes critical concepts and settle a panorama of crossing of the "ironic artwork" in its different supports and actions.
\end{abstract}

Keywords: Contemporary Art, irony and criticism.

Cena 1: $O$ espectador abre uma porta e adentra numa sala escura e coberta com uma camada espessa de talco. Os seus pés afundam. A porta se fecha. Tateando as paredes desta sala, ele encontra uma porta.

Cena 2: Ao abrir esta porta, ele adentra numa nova câmara - um corredor com aproximadamente 14 metros de extensão -, tão escura quanto a anterior. Um cheiro de gás, como o utilizado em nossas cozinhas, impregna o ambiente. A camada espessa de talco continua no espaço, dificultando a movimentação do espectador, que caminhando chega ao final do corredor. Encontra uma vela. Uma vela descoberta.

Portanto, agora alguma decisão deve ser tomada. Significaria a morte, este enclausuramento cheirando a gás e prestes a explodir? Cildo Meireles ativa um circuito irônico em Volátil (1980-94) e mais do que isso transforma o espectador em sujeito ativo da ação, em elemento de um jogo sarcástico e - por quê não? - perverso.

O jogo aqui é transformado em tomada de posição. Não estamos mais falando numa manipulação por manipulação, como é o caso dos jogos ópticos ou a manipulação física de certas obras concretas, mas numa articulação entre linguagem e ação, onde a sua vida (metaforicamente) pode depender disto. Entre outras coisas, o trabalho recusa entregar-se ao gesto autoritário do conceito que capta, domina e congela. Esse gesto é solidário de uma hierarquia e uma ordem contra as quais o trabalho se insurge. Contra as quais surge. No limite, o trabalho parece murmurar: "A minha Essência está no acidente". O trabalho parece estar contra os sólidos, a política dos sólidos, "a física dos sólidos", como anuncia Ronaldo Brito. Tudo o que retém a energia, a comunicação, o que retém o

\footnotetext{
${ }^{1}$ Doutorando em Estudos da História e Crítica de Arte pelo Programa de Pós-Graduação em Artes Visuais da Escola de Belas Artes da Universidade Federal do Rio de Janeiro e curador da Associação Cultural "O Mundo de Lygia Clark"
} 
fluxo das "densidades transformadoras" 1. A combinatória entre "gás" e vela em Volátil assim como entre singeleza e fósforos, no caso de Felipe Barbosa, questiona e alucina nossa certeza e confiança no universo dos sólidos.

Existem jogos perigosos no mundo da arte contemporânea: é a instância de um lúdico mortal, onde quebrar as regras pode ser o limite. Em Volátil, Bombanel (1970/96) e O sermão da montanba: Fiat lux (1973-79) ${ }^{2}$, todos de Cildo Meireles, e Homem-bomba (2002) e a série Bicho de pelúcia (2003-05) ${ }^{3}$, de Felipe Barbosa, o perigo existe potencialmente nos próprios materiais. No espaço fechado de Volátil, o perigo é fictício, o piso é coberto com uma camada de cinza, a iluminação é feita apenas por uma vela, e um odor de gás natural impregna o ambiente.

As caixas de fósforo empilhadas, usadas em O sermão da montanha: Fiat lux, tinham mais do que a sensação, o potencial de causar uma explosão. "O perigo é um elemento constitutivo dessas obras. Psicologicamente, quando se entra em contato com o perigo, os sentidos se tornam mais alertas: não se vê apenas, mas sente-se, raciocina-se com maior intensidade" ${ }^{4}$, diz Meireles.

Entretanto a ironia não se faz presente apenas no mundo perigoso da pólvora, outras situações poderão ativar a potência da ironia. Mas mesmo antes destas experimentações entre arte e matemática ou entre ação e explosão, em 1931, acontece um evento marcante para a história da arte brasileira. De início sem tanta relevância artística, mas com certeza muito mais agressivo em termos culturais: a Experiência $n^{\circ}$ 2, realizada por Flávio de Carvalho. Numa São Paulo provinciana e católica, ele resolve testar os limites da tolerância de uma massa religiosa regulada por códigos de comportamento bem rígidos. Durante uma procissão de Corpus Christi, usa um boné verde de veludo e caminha de forma atrevida na contramão do fluxo de fiéis. Hoje parece insignificante, mas para a época essa atitude - manter um boné à cabeça - era algo extremamente agressivo. Resultado: o artista só escapou de um linchamento graças à intervenção da polícia. O conflito surgia do embate entre o corpo físico e fragmentário do artista e o corpo místico dos fiéis e seu totem.

Alguns meses depois, Flávio de Carvalho lança um livro onde tenta compreender a tensão desencadeada pela sua experiência/provocação. É curioso, como acentua Luiz Camillo Osorio, que "ao longo de todo o livro não apareça a palavra arte ou artístico em nenhum momento para definir o ocorrido" 5. A atitude de Carvalho estabelece um processo de vinculações diretas entre a Experiência e a performance, apesar do fato de não ter sido um acontecimento artístico, há um caráter mais trágico: o do indivíduo, solitário, à mercê de uma massa em fúria.

Diferentemente do que seriam as performances de Allan Kaprow, cujas probabilidades gerais são previstas e das quais pode-se a rigor lembrar, a Experiência de Flávio de Carvalho não comporta nem diálogo nem roteiro, é propriamente inenarrável. Não que seja deixada ao acaso e não dê margem a nenhuma previsão. A Experiência acaba por congregar uma acentuação muito maior do instante presente, do momento da ação. Isso cria a característica de rito, com o público não sendo mais só espectador, e sim, estando numa espécie de comunhão. A característica de evento da Experiência (já que ela foi única, não se repetiu) acentua essa condição, dando ao público uma característica de cumplicidade, de testemunha do que aconteceu.

Investigar o próprio corpo, apresentá-lo numa situação em discordância com as convenções comportamentais de um determinado tempo e local, provocar, deixar o corpo em liberdade total para o uso agressivo de outros, dedicar-se a observar suas funções íntimas, investigar suas potencialidades sensoriais, seu perfil moral, significa transgredir um 
dos principais tabus de nossa sociedade, que regula cuidadosamente, por meio de proibição, a distinção entre o corpo e a alma. Pôr o bom senso ou o senso comum em suspenso foram tarefas que a Experiência trouxe em seu sentido pleno. Como o artista assinala em seu texto, sua atitude arrogante nada mais era que uma experimentação, que buscava testar a agressividade de uma multidão religiosa e os seus limites de civilidade e tolerância.

Contemplei por algum tempo este movimento estranho de fé colorida, quando me ocorreu a idéia de fazer uma experiência, desvendar a alma dos crentes por meio de um reagente qualquer que permitisse estudar a reação nas fisionomias, nos gestos, no passo, no olhar, sentir enfim o pulso do ambiente, palpar psiquicamente a emoção tempestuosa da alma coletiva, registrar o escoamento dessa emoção, provocar a revolta para ver alguma coisa do inconsciente. Dei meia volta, subi rapidamente em direção à catedral, tomei um elétrico e meia hora depois voltava munido de um boné. ${ }^{6}$

Seguindo esta linha destrutiva de valores e renovando uma linguagem através de uma atitude de guerrilha, a Caixa de baratas de Lygia Pape (1967), a mala de Para um jovem de brilhante futuro (1974) de Carlos Zílio ou a performance de Antonio Manuel no Salão Nacional de Arte Moderna de 1970, no MAM, quando inscreve seu corpo como uma obra, é rejeitado pelo júri e à revelia das autoridades culturais apresenta-se nu no evento, são dilemas de resistência numa ditadura (política e corporal). Combate contra políticas de segregação artística (o espaçamento museológico versus as 'trouxas' de Artur Barrio) e social (como os 'caixões' em Uma-quente, de Antonio Manuel em 1968). A política corporal, o corpo sendo 'usado' para uma produção artística é, muito mais do que 'crítica', uma resistência. Palavra de inúmeras possibilidades semânticas, resistência, aqui, significa não ter medo, continuar a todo custo. A resistência é afrontamento, relação de força, situação estratégica. Não é um lugar, que se ocupa, nem um objeto, que se possui. Ela se exerce, se disputa. Neste caso, a ironia serve como metáfora de (re)existência ou tomada de posição. Numa época de corpos torturados, eletrochoques, desaparecimentos, massacres e mortes, a relação corpo/poder se mostrava institucionalizada. O homem se exerce como produção deste poder e a ironia como meio de se fazerem circular as ações. O que fazer com uma nota de "zero cruzeiro"? Objetivamente isto não conta e não vale nada. Mas o que a "inserção" tematiza é a espécie de inteligência, a espécie de discurso, "a espécie de sociabilidade que movem essas insignificâncias" " . O importante não é o conteúdo, mas a estrutura dessa comunicação volátil: um certo murmúrio coletivo que não cessa de acontecer. A ironia em constante circulação dentro de um percurso aparentemente aleatório, misturando-se ao acaso e ao anonimato.

Estas ações fundamentalmente procuravam questionar critérios, por meio de situações ou obras que utilizavam uma certa ironia para obter o seu resultado, porém Nelson Leirner, em dezembro de 1967, também questionou a autoridade de instituições de um modo até então inédito. $\mathrm{O}$ artista enviou um porco empalhado ao Salão Nacional de Brasília e este foi aceito. Logo após, o artista manda uma carta aos membros do júri de seleção com a seguinte pergunta: "Qual é o critério dos críticos para aceitarem esse trabalho no Salão de Brasília?”. Nesse episódio, Leirner não está jogando apenas contra ou provocando - a equipe de críticos. Ele provocava da mesma forma sua categoria profissional - os próprios artistas -, uma vez que fez questão de frisar que aquela era a primeira vez que alguém colocava em dúvida os critérios daqueles que haviam escolhido seu trabalho. Colocando-se contra a crítica e os próprios colegas (tanto aqueles recusados como os aceitos no Salão, como ele), o artista estava questionando, em última instância, 
todo o sistema de arte, com suas regras nem sempre cristalinas, seus acertos tácitos, sua rede de cumplicidades. Até então, os raríssimos artistas a colocarem em dúvida os critérios de um júri de salão foram aqueles que tinham seus trabalhos recusados. E, para esses, a melhor resposta sempre foi insinuar, ou afirmar com todas as letras, que tal dúvida era motivada pelo despeito de não terem os trabalhos aceitos. Agora, alguém que havia ingressado no salão, perguntar sobre os critérios?

Num evento simbólico, Ferreira Gullar sugere, em 1960, a Reinaldo Jardim e Hélio Oiticica:

Devíamos fazer o seguinte: pegar o nosso objeto e realizar um ato de terrorismo. A gente pega os objetos e solta nas praças, nos jardins e tudo que é canto, quando amanhecer está lá (...) era uma coisa inteiramente maluca, porque era a antecipação de tudo que aconteceu depois. Era arte na rua como acontecimento. ${ }^{8}$

O Neoconcretismo era muito mais do que se podia imaginar, ou o que Gullar imaginava que fosse:

\begin{abstract}
Nós anunciaríamos a exposição neoconcreta com vernissage às cinco da tarde e encerramento às seis. Então colocaríamos um dispositivo em cada uma das obras, e um detonador único num canto do vernissage. Quando marcasse seis horas, a exposição detonaria e tudo explodiria. O Oiticica disse: 'Pô, mas eu não vou destruir minhas obras não!' No fundo era a expressão do impasse, ao qual eu queria dar a solução possível. Daí o Oiticica suou muito, vacilou mas disse: 'Não, eu não faço esse negócio’. ${ }^{9}$
\end{abstract}

O impasse era dado. A participação do espectador dentro do "projeto" neoconcreto chega ao limite. Participação e crítica ao sistema vigente, Gullar propunha uma ação que confirmava o isolamento e a dificuldade de encontrar uma saída para a veiculação dos neoconcretos.

Entretanto, Homem bomba, Bicho de pelúcia e Bombanel não deixam espaço para a hesitação. A aparente singeleza de um boneco construído com fósforos é desmistificada com o seu acendimento. Tal como a inocência de um urso de pelúcia e a pólvora sendo transportada dentro de um anel podem ser um fator de perigo para o espectador mais afoito. É o "projeto explosivo brasileiro" tomando o lugar da inocência construtiva ou de uma geometria sensível que finalmente identifica limites em sua exploração. Estas situações 'explosivas' não interessam enquanto forma, organismo, mas como possibilidade, expectativa, imprevisibilidade. O dado principal destes trabalhos é o lúdico em conjunto com a ironia e um certo humor negro. Estas obras conseguem subverter a ordem dos fatores e aliam perversidade e sedução no mesmo objeto. São situações incômodas que põem o espectador numa situação de escolha: as aparências definitivamente enganam. Possuem uma violência, mas estão sob controle... Pelo menos por enquanto: "Estou fazendo uns maiores [o artista refere-se ao trabalho Homem bomba] com morteiro. Desde o inicio da série, eu quis fazer com toda a linha de morteiros: com doze tiros, três e um, além das bombinhas. Ai é sério". O artista faz o alerta, reconhece que há limites, encontra as fronteiras que guardam este tipo de trabalho: "Se eu continuar com esta idéia, é risco de morte! Tudo tem um limite. Se você [o artista faz um aviso aos colecionadores] quiser o homem com 12 tiros, eu faço, mas não o deixarei na minha casa" ${ }^{10}$.

Citando Bombanel, Cildo Meireles argumenta com uma certa perversidade e um gracejo infantil: "Esta obra faz parte da série Condensados. Uma série de miniaturas de antigos trabalhos [da série Arte física]. Este é a miniatura de um barril de petróleo em forma de anel. Ele tem o vidro como uma lente, que converge a luz solar para um determinado 
foco. Mais duas camadas de vidro e finalmente, em sua base, pólvora. A distância focal deste lente está direcionada para a pólvora". E o artista continua relatando a sua obra: "É como uma brincadeira de criança: o menino brinca com a lente e a folha de papel, que depois de alguns minutos, queima com a luz do sol" ${ }^{11}$.

A ironia se re-configura. Sua leitura também pode ser feita no âmbito das ilusões. Há as obras que lidam com o jogo da aparência, como as xifópagas capilares de Tunga e Eureka/Blindhotland ${ }^{12}$ (1970-75) de Cildo Meireles. Estas situações não interessam enquanto coisa, forma, organismo, mas como possibilidade, expectativa, imprevisibilidade. $\mathrm{O}$ dado principal destes trabalhos é o lúdico em conjunto com a ironia, um certo humor negro. A verdade nem sempre é o que imaginamos (ou no caso, enxergamos) ser. O fascínio e a beleza estética podem nem sempre ser uma experiência agradável.

A multiplicidade de ações da ironia e do sarcasmo veio propor tensões, iminências e desequilíbrios materiais, sempre a nos defrontar com situações espaciais-limites: a investigação por excelência do objeto de arte, mas como vontade de surpreender, expor e re-inventar a própria existência.

Colocando em questão a possibilidade de a arte integrar-se na coletividade, transformando-a, a sua inscrição se dá incorporando as contradições entre o trabalho e o circuito. Não se trata apenas de uma política de defesa intransigente de um espaço da contemporaneidade. O que está em jogo é "a liquidação definitiva do sistema das BelasArtes" "13, como dizia José Resende e Ronaldo Brito, e a criação de outros meios de circulação das obras. O esforço parece colocar em abismo o código vigente, a leitura do Real. Todas as obras abordadas nesta pesquisa surgem como provocação do espaço, colocam em xeque um aprisionamento do Ideal ou uma certa verdade eterna. Outra espécie de manobra vai segurá-la. A ironia aparece como (des)articuladora deste espaço de aparências, ou representações metafóricas, e oferece novas táticas para esta circulação através de uma estrutura de jogo. Jogo de palavras, de metáforas, alegorias, de aparências, ilusões.

A geometria passa a se tornar coisa, uma entidade material, mas aliada a uma perversidade. Sua escala não se restringe exclusivamente a uma projeção intelectual sobre o mundo, um olhar intangível, mas remete-se direta e simultaneamente ao dado físico do sujeito que usufrui elementos tão corriqueiros quanto palitos de fósforos, estalinhos, anéis ou brinquedos. No caso de Barbosa, um aspecto ao qual os seus trabalhos colocam dizem respeito a sua construção. Nenhum deles foi obtido pela sobreposição de uma estrutura externa artificial, eles encontram sua "resultante" nos encaixes e conjunções que parecem se anunciar espontaneamente. A aparente precariedade destas estruturas acaba por dar continuidade, mesmo não sendo sua intenção primordial, a um deslocamento já anunciado pelas vanguardas construtivas brasileiras: a invenção, como elemento simultâneo de apropriação e desapropriação de elementos, formas e técnicas corriqueiras do nosso dia-adia ${ }^{14}$. É importante deixar claro que as obras abordadas neste ensaio não seriam a primeira onda de um levante irônico dentro do panorama das artes visuais brasileiras no século XX, mas um conjunto significativo de trabalhos que aliaram uma identidade irônica (em alguns casos identificáveis por este autor como embates ao paradigmático projeto construtivo brasileiro) a uma perversidade, muitas vezes conjugada na pólvora, e por isso mesmo levada a limites extremos.

A ironia e uma certa referência ao fim de um "projeto construtivo" presente tanto na aglomeração e orquestração dos materiais agregados ao boneco de Homem bomba quanto na sua queima, acabam permeando a ação, já que o "projeto explosivo" acaba tomando 
direções que não haviam sido problematizadas pelo artista: o lado irônico é acentuado no descontentamento da vizinha ao quintal em que é feita a explosão do boneco. A impaciência e a raiva com o estouro do boneco revelam uma situação tão desconfortável (e explosiva) quanto o próprio ato em si. Examinando espaços e processos de comunicação, as condições de espectador e autoria, o jogo de aparências de Barbosa põe em questão situações que vão da política a estratégias que re-pensam a questão da Ética na Arte.

Isso não deve causar surpresa: é inerente ao processo artístico colocar em crise os dogmas, seja isso mediante sua simples manifestação ou através de ironia, de referências sarcásticas ou o grotesco. Acaba instaurando a relação arte-corpo como um contato direto entre emissor e receptor. É a instituição do aqui-agora. No espaço da Arte, o espectador não sabe o que vai ver e, mais do que isso, talvez nem esteja familiarizado com o tipo de manifestação a que assiste ou participa.

A experiência acaba sendo o nó de articulação do sentido, a ação que se orienta à produção da obra e à contemplação das manifestações artísticas. Objeto estético, criação e percepção, ganham sentido e significação quando a experiência instaura a relação com o mundo e com os outros. "Não mais a obra de arte como instrumento de transmissão de mensagens, idéias ou essências; sim, comunicação: ação que vincula instaurando sentido e significação na expressão, no fenômeno" " ${ }^{15}$. Na obra de Barbosa, a idéia era criar um campo de objetos visualmente inocentes que na realidade mentiam sobre sua aparência visual; houve uma inversão da percepção normal. À medida que o espectador se aproxima destes objetos, ele descobre o indício do perigo. Chega o momento da decisão: afastar-se ou não? Deixar-se mergulhar nesta instância perigosa? Caso concorde, o espectador experimenta e entra em contato com um corpo em (de)composição incendiária. A periculosidade do objeto provoca no espectador uma reorganização de suas referências. Redefinições de seu próprio corpo a partir de elementos externos. Um espírito que faz do artista algo próximo à figura de um Tentador: assume o risco como elemento intrínseco ao seu trabalho.

\section{Bibliografia:}

BRITO, Ronaldo. Freqüência imodulada. In: MEIRELES, Cildo. Cildo Meireles. Rio de Janeiro, FUNARTE, 1981.

CARVALHO, Flávio de. A Experiência n.2: realizada sobre uma procissão de Corpus-Christi: uma possível teoria e uma experiência. Rio de Janeiro: Nau, 2001.

COCCHIARALE, Fernando; GEIGER, Anna Bella. Abstracionismo geométrico e informal: a vanguarda brasileira nos anos 50. Rio de Janeiro: FUNARTE, 1987.

FERREIRA, Glória; TERRA, Paula (org.). Situações: arte brasileira - anos 70. Rio de Janeiro: Fundação Casa França-Brasil, 2000.

GÓMEZ, Diego Léon Arango. Experiência e Expressão Artísticas como Fundamentos para uma Crítica da Arte em Merleau-Ponty. 1991. Tese (Dissertação em Filosofia) - Departamento de Filosofia, Universidade Federal do Rio de Janeiro, Rio de Janeiro.

HERKENHOFF, Paulo; MOSQUERA, Gerardo; CAMERON, Dan. Cildo Meireles. São Paulo: Cosac \& Naify, 2000. 
OSORIO, Luiz Camillo. Flávio de Carvalho. São Paulo: Cosac \& Naify, 2000.

SCOVINO, Felipe. Entrevista com Cildo Meireles. In: 19 de outubro de 2005. . Entrevista com Felipe Barbosa. In: 19 de abril de 2006.

1 BRITO, Ronaldo. Freqüência imodulada. In: MEIRELES, Cildo. Cildo Meireles. Rio de Janeiro, FUNARTE, 1981, p. 8.

${ }^{2}$ N.A. Bombanel é uma peça de metal, em formato de prisma, tendo no seu interior uma pequena quantidade de pólvora. Fiat Lux compreende uma área de aproximadamente $60 \mathrm{~m}^{2}$, circundada por oito espelhos de 1,60 x 1,20 m, na superfície dos quais estavam escritas oito bem-aventuranças do sermão da montanha (Mateus, 5, 3-10). No centro desta área, estão empilhadas 126.000 caixas de fósforos. O chão era revestido de lixa preta. O som do atrito dos pés sobre a lixa foi gravado e amplificado. Do trabalho participavam ainda cinco atores. Realizada a 25 de abril de 1979, no Centro Cultural Candido Mendes, no Rio de Janeiro, a exposição durou apenas 24 horas.

3 N.A. Homem bomba compreende um boneco de aproximadamente $44 \mathrm{~cm}$ de altura e $20 \mathrm{~cm}$ de largura, constituído unicamente por 'bombinhas' (explosivos com pequeno poder de destruição, caso não sejam usados em grande quantidade). A obra discutida neste ensaio é o vídeo Homem bomba (VHS, 10', 2002), realizado pelo artista, que mostra a queima deste boneco. Bicho de pelúcia é uma série que compreende entre outros: Panda, Teddy bear e Ursa maior. São ursos de pelúcia, que tiveram o seu tecido de pelúcia retirado e foram cobertos com estalinhos coloridos. Nesta ensaio não estaremos abordando nenhum urso em específico, mas o seu conjunto..

4 Cf. Herkenhoff, Paulo; MOSQuerA, Gerardo; CAMERON, Dan. Cildo Meireles. São Paulo: Cosac \& Naify, p. 35 (entrevista a Gerardo Mosquera).

${ }^{5}$ OSORIO, Luiz Camillo. Flávio de Carvalho. São Paulo: Cosac \& Naify, 2000, p. 20.

${ }^{6}$ Cf. CARVALHO, Flávio de. A Experiência n.2: realizada sobre uma procissão de Corpus-Christi: uma possível teoria e uma experiência. Rio de Janeiro: Nau, 2001.

${ }^{7}$ BRITO, Ronaldo. Freqüência imodulada. In: MEIRELES, Cildo. Cildo Meireles, op. cit., p. 9.

8 GULLAR, Ferreira. Depoimento. In: COCCHIARALE, Fernando; GEIGER, Anna Bella. Abstracionismo geométrico e informal: a vanguarda brasileira nos anos 50. Rio de Janeiro: FUNARTE, 1987, p. 97.

${ }^{9}$ Idem, ibidem.

${ }^{10}$ Cf. Entrevista concedida ao autor em 19 de abril de 2006.

${ }^{11}$ Cf. Entrevista concedida ao autor em 19 de outubro de 2005.

12 "Num ponto iluminado, circundado por redes, o espectador primeiro vê duzentas bolas de borracha preta, acreditando erroneamente serem idênticas (...) uma trilha sonora com o som de cada bola caindo dá uma pista, mas é apenas por meio da interação física que se pode tomar consciência de seus pesos distintos. Essa é Blindhotland. O segundo elemento da instalação, consiste num par de balanças colocadas sobre uma estaca. Vemos que alguns objetos postos sobre as balanças são perfeitamente iguais em peso, contradizendo mais uma vez a lógica do olhar. Vêem-se duas peças de madeira que têm o mesmo peso que uma cruz feita de dois pedaços idênticos de madeira, que se interseccionam em sua parte central. Aparentemente, três bocas têm o mesmo peso que uma" (Cf. HERKENHOFF, Paulo; MOSQUERA, Gerardo; CAMERON, Dan. Cildo Meireles, op. cit., p. 66).

${ }^{13}$ José Resende e Ronaldo Brito, in: Mamãe Belas-Artes, Caderno de Texto, nº 2, Espaço ABC/Funarte apud FERREIRA, Glória; TERRA, Paula (org.). Situações: arte brasileira - anos 70. Rio de Janeiro: Fundação Casa França-Brasil, 2000.

${ }^{14}$ Como o tecido nos Parangolés de Oiticica, a terra nos Bólides ou o alumínio nos Bichos.

15 GÓMEZ, Diego Léon Arango. Experiência e Expressão Artísticas como Fundamentos para uma Crítica da Arte em Merleau-Ponty. 1991. Tese (Dissertação em Filosofia) - Departamento de Filosofia, Universidade Federal do Rio de Janeiro, Rio de Janeiro, p. 29. 